\title{
Neorealism: Unifying Cognition and Environment
}

AQ: au

AQ: 1

AQ: 2

\author{
François Tonneau \\ Federal University of Pará, Pará, Brazil and University of Minho, Braga, Portugal
}

\begin{abstract}
Recent trends in psychology have revealed increasing discontent toward representational explanations of behavior. However, whether these trends have the conceptual resources to address the full range of cognitive phenomena remains unclear. Here, I defend neorealism (Holt, 1914) as the missing philosophical link between radically embodied cognitive science and a more encompassing psychology. Neorealism identifies cognitive contents, however subjective or unreal in appearance, with portions or cross sections of the objective environment. These portions are extended in time and they sustain causal and historical relations to current behavior. I sketch how neorealist concepts can help psychologists to address phenomena such as dreams and imagery in fully environmental terms.
\end{abstract}

Keywords: neorealism, direct realism, embodied cognition, ecology, unifying psychology, theory of psychology

Eu não canto o fado, o fado é que me canta. —Amália Rodrigues (1920-1999)

Psychology was born in disunity and remains in disarray. From its historical roots in 19th-century psychophysics, psychopathology, mental testing, social science, and biology, psychology has always reflected various conflicting orientations (Koch, 1993). Conflicts have ranged from empirical to methodological to philosophical (Goertzen, 2008). The few strategies that have been proposed toward unification have met with little success and remain as fragmented as the discipline itself (Yanchar \& Slife, 1997). This state of affairs is hardly surprising because it reflects fundamental disagreements on several philosophical options.

A first disagreement, or fundamental choice point, concerns the scientific nature of psychology. Should psychology be a natural science? Researchers with a cognitive, behavioral, or biological orientation answer in the affirmative whereas proponents of humanistic or hermeneutic approaches argue that psychology as a natural science is incomplete at best (Koch, 1981). Those who defend the project of a scientific psychology do so, presumably, because they think that the project is worth trying - that the potential good of psychology as a natural science will prevail over any possible harm. Their choice cannot be shown to be correct a priori, but it may eventually be justified by its fruits. So far, although the successes cannot be denied, they seem small in relation to remaining needs and to the amount of effort that has been invested in developing psychological science.

Disagreements also abound within the natural science approach to psychology. Some concern the subject matter of psychological

François Tonneau, Center for Theory and Research, Federal University of Pará, Pará, Brazil, and School of Psychology, University of Minho,

AQ: 3 Braga, Portugal.

Correspondence concerning this article should be addressed to François Tonneau, Universidade Federal do Pará, Núcleo de Teoria e Pesquisa do Comportamento, Rua Augusto Corrêa, 01 - Guamá, Belém - PA, 66075110, Brasil. E-mail: francois.tonneau@gmail.com studies (Brunswik, 1952). Should psychology address experience, behavior, the internal mechanisms that make the latter possible, or any and all of the above? Again, the issues are primarily philosophical and involve different ontological interpretations of psychological phenomena (Smith, 1988). For example, does the mind consist in behavior or in something else (Rachlin, 2012)? Although scientific psychologists differ widely in terms of their ontological views and proposed subject matter, one methodological principle has commanded broad agreement: Psychological explanations are to be evaluated by examining behavior. This methodological behaviorism (a result, in part, of Watson's, 1913 manifesto) is no guarantee against triviality of results, but it constitutes a common ground for comparing different theories as well as different theoretical approaches.

In this respect, it is important to note that the role of scientific paradigms and their incommensurability, as well as the alleged theory-ladenness of data, have been overrated by psychologists. In psychology as well as elsewhere, differences among paradigms do not have any radical implication for theory testing (Sankey, 1997), and data do test theories in an independent fashion (Franklin et al., 1989). Thus, as long as they are empirically grounded, and regardless of who raises them, objections to one's theoretical outlook must be taken seriously. They cannot be dismissed as a symptom of paradigm incommensurability and then set aside. Rather, they signal the need to adapt one's explanations, and in some cases, to modify one's conceptual resources so as to accommodate empirical inadequacies.

\section{The Need for Neorealism}

In recent years, several researchers have been increasingly critical of representational explanations of behavior and of the representational theory of mind. Under the labels of embodied, enactive, or extended cognition (e.g., Chemero, this issue; Di Paolo, this issue; Hutto, this issue), these researchers emphasize the richness of animals' (and people's) ecological environment and how it provides guidance to action. Their explanations of cognitive performance typically appeal to the mutual dynamics of environment and behavior in the form of ongoing feedback loops (Nielsen, 
2010). In all cases, these approaches take an organism's environment as constitutive, at least in part, of cognition, and they stress the importance of identifying the features of the organism's surroundings that are actually related to behavior (Turvey \& Carello, 1981).

An obvious problem for these research programs is to account for the sort of cognition that occurs without any apparent input or any feedback loop that could guide current behavior (Grush, 2002). Mental imagery, problem solving "in one's head," and language production are common examples of the phenomena that motivated representational accounts in the first place. Failing to account for them would invalidate a general account of the mind in terms of direct perception (e.g., Chemero, 2009) and severely restrict the scope of ecological, nonrepresentational psychology.

Here, I will argue that the conceptual resources of ecological and direct perception approaches can be extended so as to explain mental images, dreams, and more generally the cognitive phenomena that seem to take place in the absence of any environmental input. The needed conceptual extension is the philosophical framework of neorealism or new realism, pioneered by Edwin B. Holt and his colleagues in the early 20th century (Holt et al., 1910, 1912). Neorealism was quickly overshadowed by behaviorism, but a modernized version can address adequately the very problems that plague nonrepresentational approaches to cognition (Tonneau, 2011a).

I will proceed at a framework level by developing a set of neorealist theoretical concepts that extend direct cognition in more inclusive directions. I have no new data to discuss. Instead, my strategy will be to show that the data commonly taken to support representationalism can in fact be explained in strictly environmental terms. I will conclude with some brief methodological recommendations that are neither required by neorealism nor specific to it, but they are, I think, needed to move psychology forward.

\section{The Organism and the Cross Section}

Neorealism is a kind of radical environmentalism in the sense of Chemero and Silberstein (2008). The basic philosophical thesis of neorealism is that the contents of cognition (in particular, the contents present in thought and consciousness) are parts of the environment that fulfill specific functions with respect to behavior. In particular, consciousness is an external relation between the knower and the known "and does not denote a special stuff or way of being" (James, 1904, p. 486).

An implication of this thesis at the level of scientific research is that psychologists should analyze the environment so as to discover which functions it fulfills and in which conditions. Living organisms never interact with the totality of the word at one time but with different parts of the world at different times. The part of the world with which an animal is interacting at any given time is called a cross section of the environment (Holt, 1914).

Now there are obvious physical and geographical restrictions on which parts of the environment, or cross sections, can influence an organism's behavior at any given time. In many cases, the possibility of an object $\mathrm{X}$ affecting behavior depends on a medium of contact, such as ambient light (Gibson, 1979; Kantor, 1921). In other cases, an appropriate medium of contact is present, but $\mathrm{X}$ fails to affect behavior unless other conditions (say, of a motiva- tional type) are fulfilled. For instance, right now I do not tell anyone what is in front of me, but I would if somebody asked me. In these cases, let us say that $\mathrm{X}$ is behaviorally available: A part $\mathrm{X}$ of the environment that is currently available does not necessarily affect behavior, but it would do so under additional conditions. (Hence, the concept of availability is dispositional. However, availability is a disposition of the environment with respect to an organism, not a disposition of the organism with respect to the environment.)

The behavioral availability of some part $\mathrm{X}$ of the environment depends on the existence of a response mechanism that is sensitive to X (Holt, 1914). For example, in animals with a central nervous system, this response mechanism includes the brain and other parts of the animal's body. An important idea of neorealism is that an animal's response mechanism is never decoupled from what it is responding to (or what is available behaviorally). Comparatively speaking, animals with simple response systems are able to respond to simple cross sections of the environment whereas animals with complex response systems are able to respond to complex cross sections of the environment.

In particular, animals in which the functioning of an integrated response system depends on complex quantitative relations among the activities of its response components will respond to properties of the environment that bear equally complex relations to basic physical properties (cf. Turvey, Shaw, Reed, \& Mace, 1981). For example, in some circumstances, people asked to judge the "length" of a hand-held rod may react not to the length of the rod but to its moment of inertia around the wielding axis, a function of distance and mass (Turvey, Solomon, \& Burton, 1989). More generally, people asked to judge the magnitude of some physical variable $x$ may react instead to a combination of $n$ physical variables $x_{1}, x_{2}, \ldots, x_{\mathrm{n}}$, a combination that seems arbitrary from the perspective of fundamental physical theory, but it is nevertheless perfectly real and objective. Thus, according to neorealism, psychophysical scales do not describe relations between objective physical properties and subjective (or internal) psychological variables. Rather, these scales describe mathematical relations between two kinds of equally objective environmental properties: the simple properties that a physicist might measure (and to which the organism usually does not react) and the complex properties to which the organism does react.

Another important application of the neorealist idea of coupling concerns changes in the state of a single response mechanism over time (as opposed to variations in the response mechanisms of a population of animals). To become behaviorally available, a part X of the environment must affect the animal's response mechanism. That is, $\mathrm{X}$ must cause the response mechanism to move from one state to another. However, because causation in biology is typically baseline dependent, a causal relation between $\mathrm{X}$ and a change in the response mechanism may be possible only when the latter is in a specific baseline state (Tonneau, 2004). For example, an object A might only cause a change in the response mechanism when the latter is in state $M_{1}$, whereas another object B might only do so when the response mechanism is in another state $\mathbf{M}_{2}$. For example, a glass of water (object A) might only affect my behavior when I am dehydrated (state $\mathbf{M}_{1}$ ) whereas a blanket (object B) might only affect my behavior when I am cold (state $\mathrm{M}_{2}$ ).

Now imagine that $\mathrm{A}$ and $\mathrm{B}$ are present in the environment, that the initial state of the animal's response mechanism is $\mathrm{M}_{1}$, and that 
A causes the response mechanism to move from state $M_{1}$ to state $\mathrm{M}_{2}$ (see Figure 1). The mere fact that the animal's response mechanism leaves $\mathrm{M}_{1}$ for $\mathrm{M}_{2}$ will automatically disable any causal relation from A while simultaneously enabling $\mathrm{B}$ to move the response mechanism from state $\mathrm{M}_{2}$ to yet another state $\mathrm{M}_{3}$. Figure 1 shows what happens when three different parts of the environment ( $\mathrm{A}, \mathrm{B}$, and $\mathrm{C}$ ) require states $\mathrm{M}_{1}, \mathrm{M}_{2}$ and $\mathrm{M}_{3}$, respectively, to act on the response mechanism and therefore become behaviorally available. As the response mechanism moves from one state to another, the cross section that is behaviorally available moves from one part of the environment to another (Tonneau, 2004).

The coupling process illustrated in Figure 1 is simplicity itself. You can get an intuitive idea of how it works by placing two different objects in front of your eyes and then closing one eye and opening the other in alternation; as you do so, the part of the environment of which you are aware alternates from one object to the other. However, the neorealist concept of coupling (Holt, 1914) is surprisingly easy to misunderstand. Notice first that although the cross section and the response mechanism evolve in a parallel fashion (see Figure 1), their evolutions are entirely different matters. Whereas the response mechanism evolves by moving from one state to another, the corresponding cross section evolves by moving from one thing (or part of the environment) to another, and these things themselves do not change, at least not as a result of this process. Thus, changes in the content of a cross section are more like changing one's clothes than like changing one's facial expression. When you change clothes, it is your relation to two different pieces of clothing that changes (Tonneau, 2004). The clothes themselves do not change.

Second, the coupling shown in Figure 1 is an automatic consequence of the fact that the causal relations that the organism sustains to different parts of the environment are enabled and disabled one after the other (Tonneau, 2004). The neorealist process of coupling does not depend on any feedback loop between the environment and the organism. Such feedback loops undoubt-

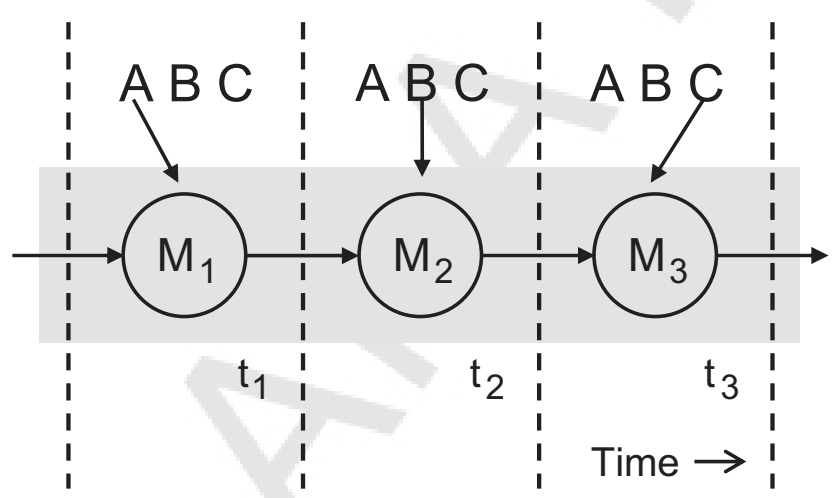

Figure 1. Changes in the content of a cross section. Time flows from left to right. $\mathrm{M}_{1}, \mathrm{M}_{2}$, and $\mathrm{M}_{3}$ are three successive states of the organism's response mechanism (taken at instants $t_{1}, t_{2}$, and $t_{3}$, respectively). As the response mechanism moves from one state to another, different portions of the environment (A, B, and $\mathrm{C}$, in this order) become available for behavioral guidance. Notice that the organism, indicated by a shaded rectangle, is extended in time. Adapted from "Consciousness outside the head," by F.

AQ: 4 Tonneau, F., 2004, Behavior and Philosophy, 32, pp. 97-123, Figure 5. Copyright $\bullet \bullet \bullet$ by $\bullet \bullet \bullet$. Adapted with permission. edly occur at many levels of analysis, and they are undoubtedly important, but they are not necessary to the parallel evolution of a cross section and the associated response mechanism (see Figure $1)$.

Finally, Holt's concept of coupling is fully compatible with the realist thesis that cognitive contents are ontologically independent of the organism's response mechanism (Holt et al., 1912). To clarify, and using a distinction first proposed by Montague (1912), whereas there is a dependency between the response mechanism and "which object" the organism is responding to, there is no dependency between the response mechanism and "the object" itself. The first kind of dependency is a result of coupling and indisputably obtains in Figure 1. At any moment, the state of the response mechanism $\left(\mathrm{M}_{1}, \mathrm{M}_{2}\right.$, or $\left.\mathrm{M}_{3}\right)$ determines which object (A, $\mathrm{B}$, or $\mathrm{C}$ ) is behaviorally available. However, the second kind of dependency, which would imply that the object available at a given time depends on the state of the response mechanism, does not follow from coupling and does not obtain in Figure 1. At any moment (say, $t_{1}$ ), the object that is behaviorally available (say, A) is completely independent of the response mechanism and would exist even if the latter did not.

Figure 1 is analogous to looking at different objects in succession. As you look at each object in turn, which thing you look at depends on the position of your eyes. At the same time, the thing you look at does not depend on the position of your eyes and would exist even if you were blind. In other words, according to neorealism, a response mechanism is always selective, not creative (Holt, 1914). Cognition consists in a bodily mechanism's responding to a (in-principle specifiable) portion of the objective and independently existing world. This portion of the word, or cross section, is the organism's cognitive content (Holt, 1914; James, 1904).

\section{Spreading Cross Sections in Time}

The neorealist explanation of cognition in terms of a cross section that shifts its content over time requires these successive contents (such as A, B, C in Figure 1) to be actually present in the environment. However, in the case of dreams, mental imagery, or more generally "silent thinking," nothing seems to fit the bill. If I dream of my grandmother or imagine a blue elephant, what portions of the environment could be identical with my thoughts?

Appearances to the contrary notwithstanding, neorealism maintains that such portions can be found-not in the environment defined over an arbitrarily short time scale, admittedly-but in an objective environment that is as extended in time as the person's own response mechanism (Tonneau, 2011a). In cases of veridical memory, neorealism identifies a person's remembrance of a past event A with A itself (or some part of it). The event A becomes behaviorally available not at the moment it occurs (say, $t$ ), but at some later time $t+x$. There is nothing surprising or illogical about this because delays between environmental events and our response to them are ubiquitous. Even the simplest unconditional reflex or stimulus-response relation has a nonzero latency, which implies that stimuli and responses are always separated in time. Whether we are dealing with a simple reflex or a complex memory phenomenon, the organism's response to some environmental event A occurs after some delay $x$. Of course, in all cases, the delayed reaction is made possible by the existence of an internal 
response mechanism that is itself extended in time, with a duration equal to $x$. Whether the situation is classified as "perception" or "memory" depends on the length of $x$ and is otherwise completely arbitrary (Gibson, 1979; White, 1985).

The neorealist concept of direct memory (as opposed to indirect, or representational memory) is important not only for experimental psychology but (also) in the context of clinical applications (Tonneau, 2011b). For example, in posttraumatic stress disorder, according to neorealism the person is not reacting to an internal representation of the traumatic event but to the event itself. Her body is extended in time, her eyes are extended in time, and her response mechanism is extended in time (Tonneau, 2011a). It is no objection that there is a delay between the original event and the person's current response. As we have seen, there is always a delay, even in the simplest reflex-and reflexes can be far from simple.

In the case of hallucinations and dreams, neorealism assumes that the person reacts to environmental patterns that are not only remote in time from the current response (as stimuli always are) but (also) involve temporal and spatial disconnections among their components. Draw two figures side by side on a sheet of paper: a red triangle on the left and a blue square on the right. Each of the two figures can be seen as a combination of color and shape: \{red, triangle\}and \{blue, square\}. However, the two figures do not exhaust the combinations of colors and shapes present on the sheet of paper. For example, the \{red, square $\}$ and \{blue, triangle\} combinations are just as real as the two figures although these pairs are made of disconnected components. The main difference between the \{red, triangle $\}$ and $\{$ blue, square $\}$ pairs, on the one hand, and the $\{$ red, square $\}$ and \{blue, triangle $\}$ pairs, on the other hand, is not in their degree of reality but in their degree of spatial connectedness.

Turning to the time domain, neorealism assumes that living organisms can react to temporally disconnected combinations of features present in their environment (Tonneau, 2004). These combinations are what people react to in the phenomenon of illusory conjunctions (e.g., Treisman, 1998). (Notice how perfectly real combinations of features are dubbed "illusory" just because they span wider temporal intervals than "real conjunctions.") According to neorealism, the person who falls prey to a hallucination is not reacting to unreal aspects of the environment. Rather, the person is reacting to (a) real combinations of components separated by wide temporal gaps while (b) failing to react to these temporal gaps (Tonneau, 2011a).

Figure 2 illustrates how reacting to temporally disconnected features of the environment can emulate a process of variable binding (cf. Minsky, 1975). The top line of the figure shows a simple situation with an object A on top of another object B. Therefore, A and B occupy two positions that bear the spatial relation, on-top-of, to each other (vertical, dashed arrow in Figure 2). The second line of Figure 2 shows the structure of a visual hallucination in which two features, $\mathrm{A}$ and $\mathrm{B}$, are separated in time from each other and from the later occurrence of the on-top-of relation. In this case, the person reacts to (a) the disconnected pair, $\{$ A, above $\}$; (b) the disconnected pair, $\{\mathrm{B}$, below $\}$; and (c) the on-top-of relation between the top and bottom positions. The victim of this hallucination would presumably describe it as "A being above B." The third line of Figure 2 shows the structure of

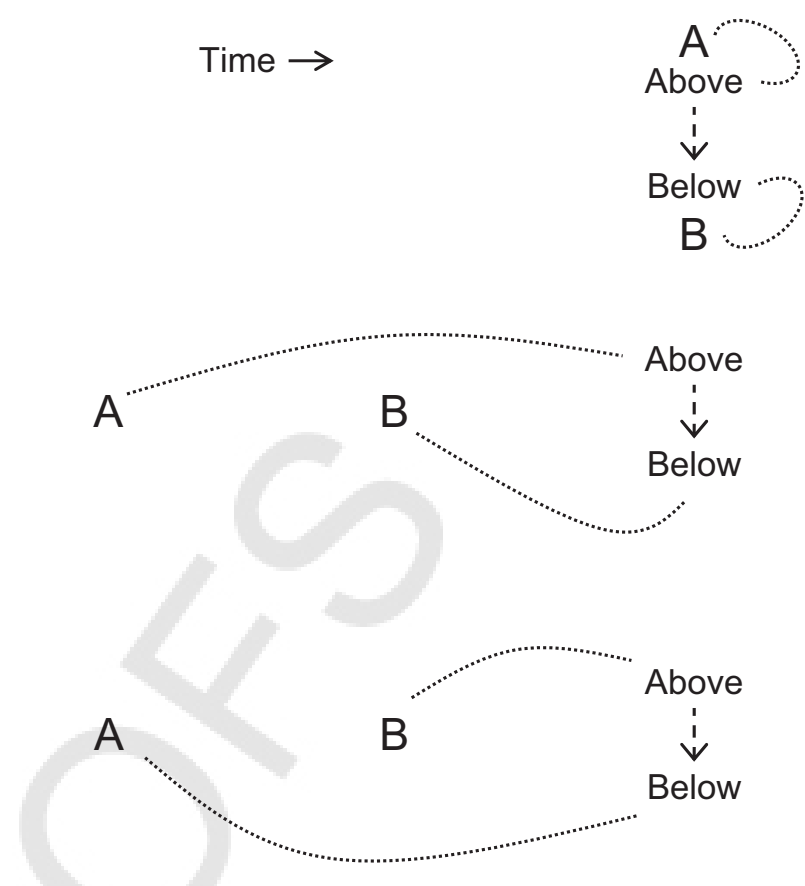

Figure 2. Relational structures in the temporally extended environment. $\mathrm{A}$ and $\mathrm{B}$ are two distinct objects or sets of features. The vertical, dashed arrow indicates the spatial relation, on-top-of, holding between two positions (one above the other). Dotted arcs relate the components of the pairs to which a person reacts. In the top line, the relational structure to which the person reacts is temporally connected. In the two bottom lines, some components of the structure are separated by time intervals that could range from seconds to years.

the visual hallucination that one would describe as "B being above A."

Replacing the spatial relation of Figure 1 (on-top-of) by a temporal relation (e.g., before or after) gives the building block of illusory movements, dynamic hallucinations, trains of thought, and dreams. In all cases, the environmental structures to which the person reacts are perfectly real and objective (Nunn, 1909-1910). What they lack is not reality, but temporal contiguity. In several well-known cases, standard conditions allow disconnected environmental structures to act on anyone with a high probability. These are called "illusions," and although that label seems to imply a response to something nonreal, they can be more simply understood as oddly featured cross sections of the environment. They span time gaps that are typically no longer than a few seconds.

However, When disconnected environmental structures start to involve longer time gaps such as days or years, the conditions under which they act (depending, as they do, on a person's extensive history of interactions with the environment) become increasingly difficult to predict. They become increasingly unavailable to third parties and are deemed irremediably "subjective" or "unreal," as in the case of dreams and hallucinations. Phosphenes also fall in this category (Manzotti, 2006).

However, in all cases, neorealism maintains that the part of the world being responded to can be discovered empirically. When dealing with shorter time scales, illusory contents can be produced by presenting stimuli in succession and controlling their nature and 
time of occurrence. The resulting illusory contents can then be related to stimulus characteristics and to the subjects' sensitivity to hallucination (e.g., Randell, Goyal, Saunders, \& Reed, 2011). For example, over a medium-scale time, experimental research is still possible by correlating features of the environment with one another and recording changes in the content of the resulting cross section (Haijiang, Saunders, Stone, \& Backus, 2006). Consistent with a neorealist view of Pavlovian conditioning (see Tonneau, 2011a, for more details), experimental research on the conditioning of perception shows that these two phenomena are really two sides of the same coin. Finally, over large time scales, experimental research becomes practically impossible, and it is necessary to turn to ethnographic, biographical, and clinical research (cf. Bentall, 1990) to uncover the conscious contents that reside in a person's entire life history.

From a neorealist perspective, the ultimate roots of subjectivity are history and context. A person can have subjectivity only to the extent that the associated cross sections are unique to her; systems without history do not have subjectivity. The disconnected structures sketched in Figure 2 are theoretically important for another reason. The different arrangements shown on the second and third line of the figure illustrate how an environment that is extended in time encompasses enough resources for systematicity and compositionality (Fodor \& Pylyshyn, 1988). The ability for the systematic combination of available units, although often discussed in relation to language, is already evident in the perception of environmental structure (Hummel, 2000). Understanding the structure of the environment is a prerequisite for understanding the structure of behavior, including language.

\section{Conclusion}

Developing a more successful version of psychology will require a synergy of philosophical background, theoretical concepts, and empirical methods that cohere with one another and are at least approximately correct as a starting point (Boyd, 1981). As a philosophy of mind, neorealism implies that psychological phenomena are constituted by the environment as it relates to behavior (Holt, 1915). Because psychological phenomena are never located in the brain, neural reductionism is rejected. Instead, neorealism emphasizes causal and historical explanations in terms of an organism's interacting with its environment.

The central concept of cross section (Holt, 1914) allows for the identification of basic psychological units that are open to modification. For example, development is seen as the modification of cross sections (and their relations to behavior) during ontogeny. Motivation and emotion refer to the behavioral availability of historical relations between the environment (including parts of the body) and previous responses. In social animals, the cross sections available to guide behavior may include cultural aspects. Neorealism rejects holism because everything is not equally connected to everything else. Neorealism focuses instead on determining the specific parts of the environment (past and present) most affecting behavior and studying how these relations become incorporated in more complex units during development (Goldfield, 1983).

Neorealism is open with respect to methods. Experimentation, although obviously needed, is not and should not be the only source of psychological knowledge. Observational studies are at least as important. In fact, they are more important than experi- mentation when the time scales of the phenomena involved make experimental control practically impossible. However, no progress will be made in psychology unless its standards of data analysis greatly improve. Especially in recent times, psychology has seen inferential statistics applied mindlessly on group data and poor measurements to the detriment of scientific understanding (Wang, 1993). With or without neorealism, progress in psychology urgently needs more detailed analyses of the interactions of individuals with their environment.

Neorealism can be summarized in one motto: taking the environment seriously. Even the approaches that grant the environment a fundamental role as a constituent of mental states have done so in a restricted fashion: most notably by limiting their quest of environmental constituents to those that are temporally connected. However, several lines of research, from radically embodied cognitive science to behavior analysis (Tonneau, 2011a), now call for theoretical integration as well as an expansion of environmental explanations beyond their traditional, self-imposed limits. By moving beyond temporal connectedness, neorealism integrates these different research programs and significantly increases the scope of radically embodied cognitive science.

\section{References}

Bentall, R. P. (1990). The illusion of reality: A review and integration of psychological research on hallucinations. Psychological Bulletin, 107, 82-95. doi:10.1037/0033-2909.107.1.82

Boyd, R. (1981). Scientific realism and naturalistic epistemology. In P. D. Asquith \& R. N. Giere (Eds.), PSA: Proceedings of the Biennial Meeting of the Philosophy of Science Association (Vol. 2, pp. 613-662). East Lansing, MI: Philosophy of Science Association.

Brunswik, E. (1952). The conceptual framework of psychology. International Encyclopedia of Unified Science, 1, 1-102.

Chemero, A. (2009). Radical embodied cognitive science. Cambridge, MA: MIT Press.

Chemero, A., \& Silberstein, M. (2008). After the philosophy of mind: Replacing scholasticism with science. Philosophy of Science, 75, 1-27. doi:10.1086/587820

Fodor, J. A., \& Pylyshyn, Z. W. (1988). Connectionism and cognitive architecture: A critical analysis. Cognition, 28, 3-71. doi:10.1016/00100277(88)90031-5

Franklin, A., Anderson, M., Brock, D., Coleman, S., Downing, J., Gruvander, A.,. . .Toering, D. (1989). Can a theory-laden observation test the theory? British Journal for the Philosophy of Science, 40, 229-231. doi:10.1093/bjps/40.2.229

Gibson, J. J. (1979). The ecological approach to visual perception. Boston, MA: Houghton Mifflin.

Goertzen, J. R. (2008). On the possibility of unification: The reality and nature of the crisis in psychology. Theory \& Psychology, 18, 829-852. doi: $10.1177 / 0959354308097260$

Goldfield, E. C. (1983). The ecological approach to perceiving as a foundation for understanding the development of knowing in infancy. Developmental Review, 3, 371-404. doi:10.1016/0273-2297(83)90021-7

Grush, R. (2002). Cognitive science. In P. Machamer \& M. Silberstein (Eds.), The Blackwell guide to the philosophy of science (pp. 272-289). Malden, MA: Blackwell.

Haijiang, Q., Saunders, J. A., Stone, R. W., \& Backus, B. T. (2006). Demonstration of cue recruitment: Change in visual appearance by means of Pavlovian conditioning. PNAS: Proceedings of the National Academy of Sciences of the United States of America, 103, 483-488. doi:10.1073/pnas.0506728103

Holt, E. B. (1914). The concept of consciousness. New York, NY: Macmillan. 
Holt, E. B. (1915). Response and cognition. I. The specific-response relation. Journal of Philosophy, Psychology \& Scientific Methods, 12, 365-373. doi:10.2307/2013669

Holt, E. B., Marvin, W. T., Montague, W. P., Perry, R. B., Pitkin, W. B., \& Spaulding, E. G. (1910). The program and first platform of six realists. Journal of Philosophy, Psychology \& Scientific Methods, 7, 393-401. doi: $10.2307 / 2010710$

Holt, E. B., Marvin, W. T., Montague, W. P., Perry, R. B., Pitkin, W. B., \& Spaulding, E. G. (1912). The new realism: Cooperative studies in philosophy. New York, NY: Macmillan.

Hummel, J. E. (2000). Where view-based theories break down: The role of structure in shape perception and object recognition. In E. Dietrich \& A. Markman (Eds.), Cognitive dynamics: Conceptual change in humans and machines (pp. 157-185). Hillsdale, NJ: Erlbaum.

James, W. (1904). Does "consciousness" exist? Journal of Philosophy, Psychology \& Scientific Methods, 1, 477-491. doi:10.2307/2011942

Kantor, J. R. (1921). A tentative analysis of the primary data of psychology. Journal of Philosophy, 18, 253-269. doi:10.2307/2939401

Koch, S. (1981). The nature and limits of psychological knowledge: Lessons of a century qua "science". American Psychologist, 36, 257 269. doi:10.1037/0003-066X.36.3.257

Koch, S. (1993). "Psychology" or "the psychological studies"? American Psychologist, 48, 902-904. doi:10.1037/0003-066X.48.8.902

Manzotti, R. (2006). Consciousness and existence as a process. Mind \& Matter, 4, 7-43.

Minsky, M. (1975). A framework for representing knowledge. In P. H. Winston (Ed.), The psychology of computer vision (pp. 211-277). New York, NY: McGraw-Hill.

Montague, W. P. (1912). A realistic theory of truth and error. In E. B. Holt, W. T. Marvin, W. P. Montague, R. B. Perry, W. B. Pitkin, \& E. G. Spaulding (Eds.), The new realism: Coöperative studies in philosophy (pp. 251-300). New York, NY: Macmillan.

Nielsen, K. S. (2010). Representation and dynamics. Philosophical Psychology, 23, 759-773. doi:10.1080/09515089.2010.529045

Nunn, T. P. (1909-1910). Are secondary qualities independent of perception? Proceedings of the Aristotelian Society, 10, 191-218.

Rachlin, H. (2012). Is the mind in the brain? A review of: Out of our heads: Why you are not your brain, and other lessons from the biology of consciousness by Alva Noë (2009). Journal of the Experimental Analysis of Behavior, 98, 131-137. doi:10.1901/jeab.2012.98-131

Randell, J., Goyal, M., Saunders, J., \& Reed, P. (2011). Effect of a context of concrete and abstract words on hallucinatory content in individuals scoring high in schizotypy. Journal of Behavior Therapy and Experimental Psychiatry, 42, 149-153. doi:10.1016/j.jbtep.2010.11.002

Sankey, H. (1997). Incommensurability: The current state of play. Theoria, $12,425-445$.

Smith, T. L. (1988). Neo-Skinnerian psychology: A non-radical behaviorism. In A. Fine \& J. Leplin (Eds.), PSA: Proceedings of the Biennial Meeting of the Philosophy of Science Association (Vol. 1, pp. 143-148). East Lansing, MI: Philosophy of Science Association.

Tonneau, F. (2004). Consciousness outside the head. Behavior and Philosophy, 32, 97-123.

Tonneau, F. (2011a). Holt's realism: New reasons for behavior analysis. In E. P. Charles (Ed.), A new look at New Realism: The psychology and philosophy of E. B. Holt (pp. 33-55). New Brunswick, NJ: Transaction Publishers

Tonneau, F. (2011b). Belief modification in cognitive therapy. Clínica y Salud, 22, 257-266. doi:10.5093/c12011v22n3a6

Treisman, A. (1998). Feature binding, attention and object perception. Philosophical Transactions of the Royal Society of London, Series B, Biological Sciences, 353, 1295-1306. doi:10.1098/rstb.1998.0284

Turvey, M. T., \& Carello, C. (1981). Cognition: The view from ecological realism. Cognition, 10, 313-321. doi:10.1016/0010-0277(81)90063-9

Turvey, M. T., Shaw, R. E., Reed, E. S., \& Mace, W. M. (1981). Ecological laws of perceiving and acting: In reply to Fodor and Pylyshyn (1981). Cognition, 9, 237-304. doi:10.1016/0010-0277(81)90002-0

Turvey, M. T., Solomon, H. Y., \& Burton, G. (1989). An ecological analysis of knowing by wielding. Journal of the Experimental Analysis of Behavior, 52, 387-407. doi:10.1901/jeab.1989.52-387

Wang, C. (1993). Sense and nonsense of statistical inference: Controversy, misuse, and subtlety. New York, NY: Marcel Dekker.

Watson, J. B. (1913). Psychology as the behaviorist views it. Psychological Review, 20, 158-177. doi:10.1037/h0074428

White, K. G. (1985). Characteristics of forgetting functions in delayed matching to sample. Journal of the Experimental Analysis of Behavior, 44, 15-34. doi:10.1901/jeab.1985.44-15

Yanchar, S. C., \& Slife, B. D. (1997). Pursuing unity in a fragmented psychology: Problems and prospects. Review of General Psychology, 1, 235-255. doi:10.1037/1089-2680.1.3.235

Received April 4, 2013

Revision received April 4, 2013

Accepted April 9, 2013 